\title{
Comments from the Editor
}

\author{
R. Scott Kretchmar \\ Penn State University
}

It is impossible to comment on the content of Volume 2, Number 2 of the Journal of Intercollegiate Sport without first acknowledging and lamenting the passing of Myles Brand, former President of the NCAA. He was the driving force behind the Scholarly Colloquium and the journal. He believed fervently in the power of good scholarship to inform both practice and policy. He made the integration of athletics with the core values and purposes of higher education a primary goal of his NCAA stewardship. He was collegial, gracious, and generous to me and other Board members. Amidst his many duties and pressures, he took a personal interest in the Colloquium and the founding of the journal. With his passing, we lost an academic ally and a friend.

It is only appropriate that we dedicate this issue of the journal to the memory of Dr. Brand. We continue the work that he helped to start with renewed energy and commitment. We acknowledge that his support was crucial to any small successes this venture has had and any achievements that may lie in the years ahead.

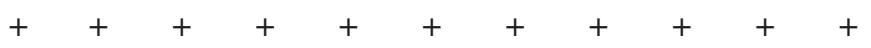

This issue of the journal begins with a Symposium of three essays on athletic reform and tax policy. Dr. Brand would have been very interested in these articles because they address the social good that intercollegiate athletics is supposed to produce in exchange for tax exemption. Several years ago Dr. Brand jousted with then Representative Bill Thomas over the NCAA's tax status. Myles argued that college athletics is a unique educational enterprise that should not be confused with professional models of sport. Because of this, he said, tax exemption is warranted. Of course, this remains a contested proposition, one that is ripe for the kind of additional analysis provided by the three papers in the Symposium.

The primary stimulus for this work came from testimony delivered by John Colombo to the Knight Commission this past spring and a related article (Colombo, 2009). Colombo suggests that tax exemption be continued ... but with conditions. Compliance with those conditions would at once, according to Colombo, effect athletic reform, promote social good in the form of education, and better align behavior in big-time sport with the letter and spirit of the tax law.

Kretchmar discusses Colombo's ideas from philosophic and educational perspectives. He examines NCAA policies and current research related to two of Colombo's key ideas-increased participation and educational accountability. He then speculates on the kinds of changes that would be needed in NCAA policy and practice if the requirements of Colombo's proposal were enforced. 
Mitten, Musselman and Burton provide a brief history of amateurism and commercialism in intercollegiate athletics, an analysis of tax law related to the NCAA, and most significantly, an alternate proposal. While sympathetic with Colombo's call for reform, they suggest that antitrust immunity (with conditions) would serve that purpose better than pressures from tax law.

Lyons and Potuto also support Colombo's interest in athletic reform, but they argue that tax law does not provide a good vehicle for bringing it about. They outline a number of practical problems-both on the side of the IRS and that of athletics-that may render Colombo's proposal unworkable. They review each of Colombo's three conditions for continued tax exemption and express doubts about cost-benefit ratios related to implementation.

This issue of JIS also broaches a rich variety of other topics in the five articles that follow the Symposium. As a group they reflect one of the purposes of JISnamely, to publish articles that are inter-disciplinary in nature. These articles include research that comes from physiology, psychology, gender studies, history, and sport management. This range of articles is important because our editorial policies support the proposition that fact, truth, insight — whatever we want to call it - is not the province of any one discipline.

Just as importantly, these articles reflect a second purpose of the journal, one of producing research from different disciplines working on a single problem. This is often identified as cross-disciplinary research. One article, for example, combines insights from sport management, ethics, and business. Another broaches a research problem found at the intersection of biology, psychology, and gender differences. Yet another includes insights from history, sociology, and management. These kinds of articles show that complex problems typically cannot be solved without the concomitant employment of multiple research tools, the kinds of tools that are not found in any single discipline.

Burton raises interesting questions about the relationships among leadership styles, gender, and perceived effectiveness in Division III athletic settings. Laudner touches on the theme of last year's Colloquium (Paying the Price: Is Excellence in Sport Compatible with Good Health?) when he reports on the kinds and rates of shoulder injuries to individuals in sports that require overhead motions. Controversial claims about "pregnancy doping" and potential athletic advantage are the topic of Sorenson's analysis. Gildea provides a fascinating historical look at the administrative battles surrounding the loss of an NCAA tradition at one member institution. Cooper revisits the issue of sport journalism and equitable gender coverage from a unique business perspective.

Other Board members and I hope that these articles both intrigue and inform. Moreover, we hope that they may serve the function ultimately of improving the sporting experience for the thousands of young people involved in intercollegiate sports at our institutions of higher education.

\section{References}

Colombo, John. (February, 2009). The NCAA, tax exemption and college athletics. Illinois Public Law Research Paper No. 08-08. Accessed on July 30, 2009 at http://ssrn.com/ abstract $=1336727$. 
Myles Brand

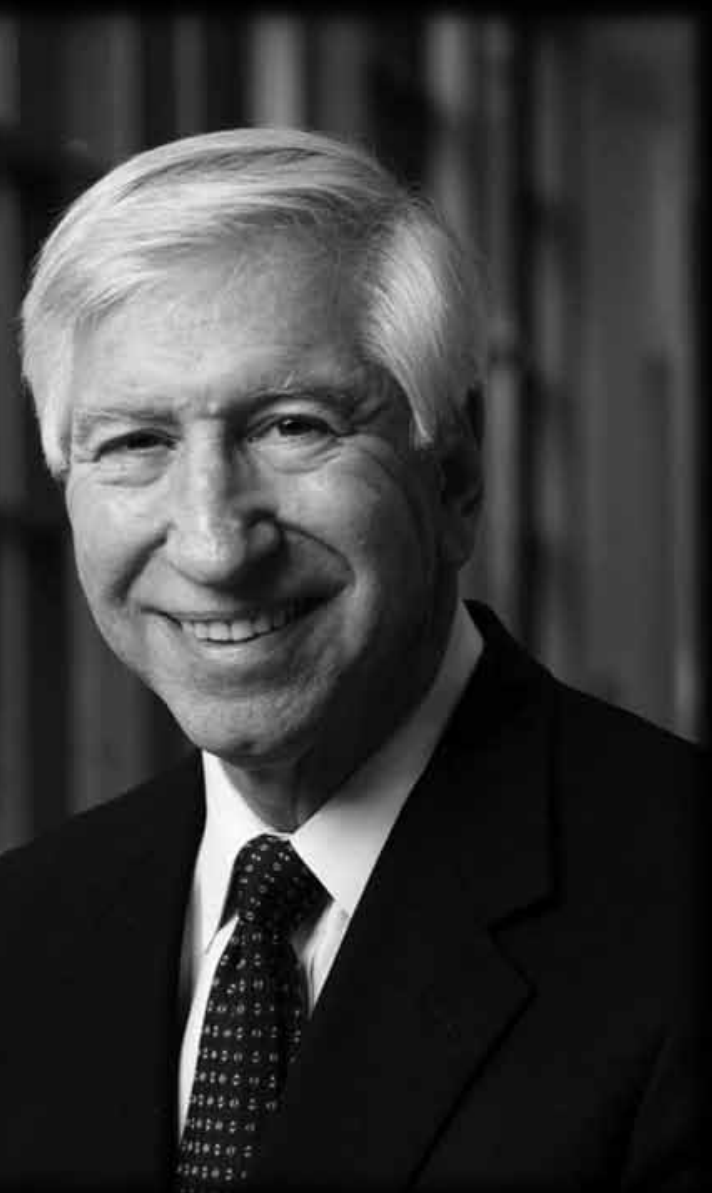

1942-2009 